\title{
COATING AND SURFACE TECHNOLOGIES FOR TURBINE AIRFOILS
}

\author{
W.S. Walston \\ GE Aircraft Engines, Cincinnati, OH
}

Keywords: coatings, bond coat, thermal barrier coating, turbine blade tip, single crystal superalloy

\begin{abstract}
The development of single crystal superalloys over the past 20 years has allowed the turbine inlet temperatures of aircraft engines to increase significantly. With further advances in superalloy temperature capability becoming more difficult, coatings and other surface technologies are becoming more important. Various approaches to improving the coating system, including both the bond coat and the thermal barrier coating are discussed. It is shown that significant improvements can be made in both components of the coating system, allowing for higher operating temperatures. While the airfoil coating system is being improved, the airfoil tips and areas below the platform of the blade must also be addressed as well. A new, high temperature turbine blade tip alloy is introduced and the application of coatings to non-flowpath surfaces are also discussed. Material improvements in the entire turbine airfoil material system will continue to allow turbine inlet temperatures to increase.
\end{abstract}

\section{Introduction}

There have been significant advances in the strength of single crystal superalloys over the past 25 years. First generation single crystal superalloys derived their strength improvements from reducing the grain boundary strengthening elements, which raised the melting points and improved the creep strength. In addition, refractory elements such as $\mathrm{W}$ and Ta were increased over prior alloys. The $2^{\text {nd }}$ generation alloys added $\mathrm{Re}$, which was a potent $\gamma$ strengthener and improved strength by lowering diffusion rates. The $3^{\text {rd }}$ generation alloys further increased the refractory element levels to achieve greater strength. Finally, the $4^{\text {th }}$ generation alloys have added Ru to improve the stability, allowing for slightly higher refractory levels and further strength improvements. These strength improvements have come at the expense of density, corrosion resistance and cost. In addition, it has become increasingly more difficult to develop an alloy with balanced properties of creep rupture and fatigue strength, environmental resistance and microstructural stability. The lack of microstructural stability is seen in long-time testing of $3^{\text {rd }}$ and $4^{\text {th }}$ generation single crystal alloys, where decreases in long time properties have been observed due to the formation of Topologically Close Packed (TCP) phases $[1,2]$. These TCP phases degrade the strength by robbing the matrix of strengthening elements such as Re, W and $\mathrm{Ta}$, and thus the strength slowly decreases as a function of time. Not only are TCP phases an issue, but a new instability termed Secondary Reaction Zone (SRZ) has been observed in alloys with more than 4 wt.\% Re [3]. The SRZ typically forms under coatings and degrades the rupture strength, but similar cellular colonies have also been observed along low angle boundaries and in dendrite cores. These cellular colonies represent a serious challenge to developing higher strength single crystal superalloys. Although it has been shown the additions of $\mathrm{Ru}$ can improve the balance of reep strength and micostructural stability, it remains a challenge to further increase the temperature capability of single crystal superalloys.

Although it is not likely that the temperature capability of superalloys will increase much further, the requirement for higher turbine operating temperatures is not diminishing. Figure 1 shows an example of the increase in the turbine inlet temperature of GE Aircraft Engine's jet engines over the past 25 years. This increase stems from a combination of material and design advances. To attempt to extract the material's contribution to this increase, the creep rupture strength increase of superalloys is overplotted on Figure 1. Starting with equiaxed alloys in the 1970's through the latest single crystal superalloys, the rupture strength of the alloys has increased nearly $150^{\circ} \mathrm{C}$. However, in this same time period the turbine inlet temperature has increased over $275^{\circ} \mathrm{C}$. The ability to continue to push the temperatures higher is due to improved cooling efficiencies and the introduction of thermal barrier coatings. With the gap in Figure 1 widening over time, further improvements in substrate materials or TBC are critical. 


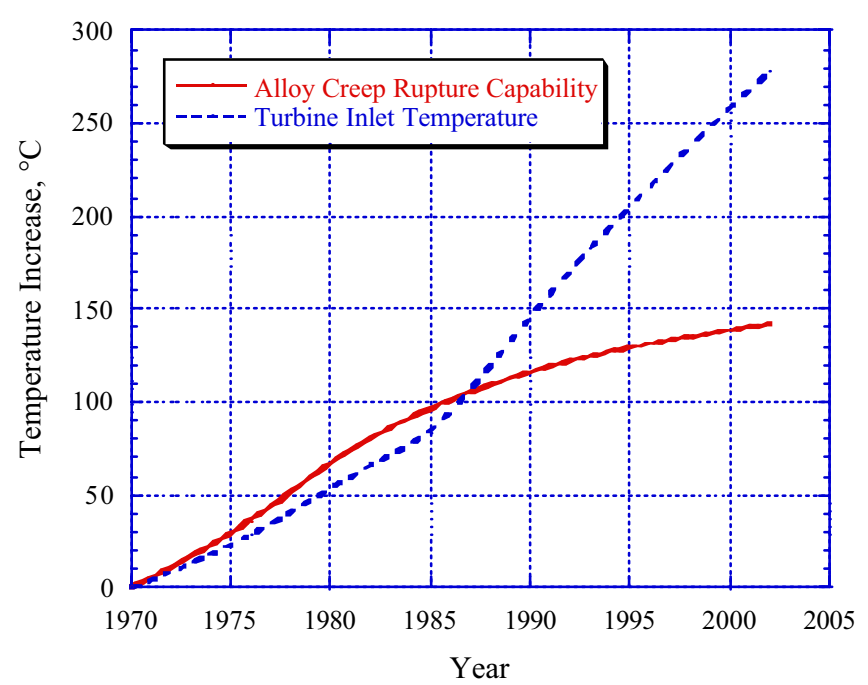

Figure 1. Increase in turbine inlet temperature compared to superalloy creep rupture strength over the past 30 years.

With the rate of improvement in superalloy temperature capability slowing, efforts to evaluate alternative materials have been increasing. Efforts are underway on materials such as $\mathrm{NbSi}$, Mo-B-Si and Ceramic Matrix Composites (CMC), but production introduction in the form of turbine airfoils is still many years away. To bridge the timeline and meet the growing engine temperature requirements, improvements in the TBC system are required. This paper will discuss advances in bond coat and TBC technologies that can address part of the required temperature increases. In addition, as the temperature of the entire turbine system increases, there are other areas of the turbine blade that must be addressed. Material improvements to the areas outside the gas path surface and the turbine blade tips will also be discussed.

\section{Bond Coat Improvements}

In the past 10 years, the importance of coatings has increased tremendously because they allow the surface temperatures of the turbine airfoils to continually increase. Many of the bond coats used for TBC's were initially derived from existing environmental coatings and not developed for the specific requirements of a bond coat. This section will discuss several new approaches to achieving longer TBC life through improved bond coats. The TBC spallation life comparisons shown below are based upon Furnace Cycle Testing (FCT) at various temperatures using standard $2.54 \mathrm{~cm}$ diameter buttons of René N5.

\section{No Bond Coat/Thin Bond Coat}

Typical bond coats to date have either been PtAl or MCrAlY coatings. Utilizing thinner bond coats, or even no bond coat, is an attractive alternative to reduce cost and weight. It must be remembered that the bond coat serves two primary functions: 1) to improve the adherence of the $\mathrm{TBC}$ and 2) to protect the substrate from environmental attack if the TBC does spall. In the case where the TBC spalls, the bond coat will likely see temperatures in excess of the intended design temperature because the hot gas path now has direct access to the bond coat, and the temperatures can be over $50^{\circ} \mathrm{C}$ hotter than with a $\mathrm{TBC}$ present. With this consideration, in order to utilize thinner bond coats, the environmental resistance of the thinner bond coat and the substrate must be adequate to survive these higher temperatures for a sufficient period of time.

The environmental resistance of the substrate can be significantly improved by utilizing lower sulfur alloys. Sulfur levels below $1 \mathrm{ppm}$ have been shown to give significant benefits to the oxidation resistance of the alloy [4,5]. Utilizing a low sulfur superalloy with a bond coat system can result in TBC life improvements [6]. If the alloy has sufficient, reliable oxidation resistance, then it is possible to utilize a "no bond coat" system [7]. Figure 2 shows that TBC life improvements can be realized by eliminating the bond coat. This is likely due to the alloy forming an adherent alumina scale that does not buckle during thermal cycling because of the higher strength of the underlying alloy compared to a bond coat. Figure 2 also shows the scatter bands for the effect on TBC life, showing a larger scatter band for the specimens without a bond coat. This is an indication that the surface preparation and chemistry are critical to achieving reproducible results.

One risk with the no bond coat approach is that, should the TBC spall, the underlying alloy does not have a significant reservoir of aluminum to provide sustained environmental resistance compared to a system with an aluminum containing bond coat. To increase the environmental resistance of the alloy without adding a thicker bond coat, a thin layer of $\mathrm{Pt}$ can be applied [8,9]. Figure 3 shows that this results in increased TBC life compared to a simple aluminide bondcoat. This thinner bond coat provides improved environmental resistance and TBC spallation life compared to the bare alloy, and does so at lower cost and weight compared to PtAl or MCrAlY bondcoats. 


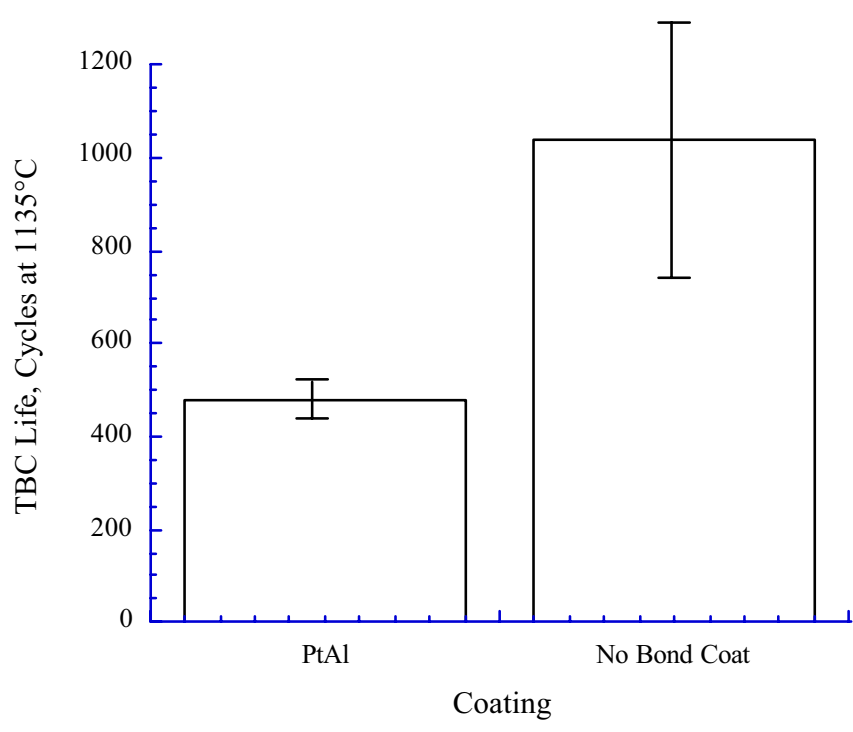

Figure 2. The average TBC spallation life of a "no bond coat" system exceeds the PtAl bondcoat, however the data scatter is larger for the "no bond coat" system.

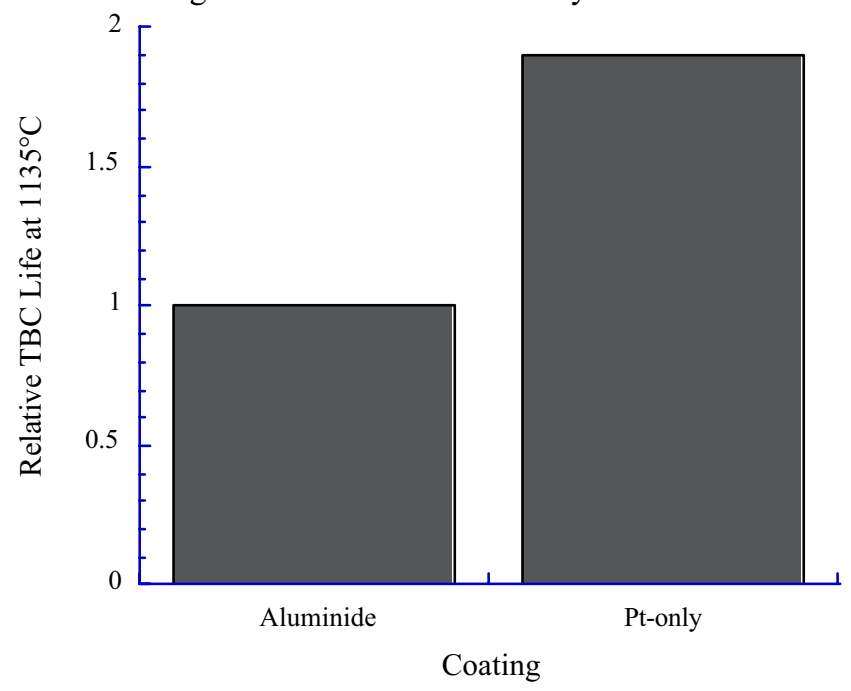

Figure 3. A thin layer of $\mathrm{Pt}$ as a bond coat outperforms a simple aluminide in TBC spallation life.

\section{$\underline{\text { PtAl Modifications }}$}

PtAl coatings have been used for many years as environmentally resistant coatings and were a natural choice as a bond coat. However, it has been realized that enhancements can be made to improve the performance of PtAl as a bond coat. As the failure mechanisms of PtAl bond coat systems have been better understood [10,11], it has become clear that there are several ways to improve the system. The PtAl bond coat system can fail by a "ratcheting" effect where the bond coat develops significant localized plastic deformation and becomes rougher as a function of thermal cycles due to the thermal expansion mismatch in the system and oxide growth stresses of the thermally grown oxide (TGO). The yield strength of the bond coat plays a critical role in this failure mechanism; thus improving the yield strength of PtAl through alloying additions would be beneficial. Another way to improve the PtAl system is by improving the ability to form a slow growing, adherent, alpha-alumina TGO scale. This can be accomplished by thermal treatments or the addition of reactive elements to reduce the oxide growth rate and improve adherence.

Modifying PtAl coatings to add $\mathrm{Zr}$, Hf and/or $\mathrm{Si}$ can improve the yield strength of the coating, as well as the TGO growth kinetics. Figure 4 shows that improved TBC life is obtained from additions of $\mathrm{Zr}$, $\mathrm{Hf}$ or $\mathrm{Hf}+\mathrm{Si}$. It is known that $\mathrm{Zr}$ and $\mathrm{Hf}$ are potent strengtheners of betaphase NiAl [12], which is the predominant phase in the PtAl coating. By strengthening the bond coat, the TGO interface stays smoother, resulting in better TBC adherence compared to unalloyed PtAl. Silicon can improve the oxidation kinetics of the coating, and under the NASA EPM program [13], various levels of $\mathrm{Hf}$ and $\mathrm{Si}$ were studied to determine the optimum composition for a bond coat. Interestingly, it was found that the optimum chemistry for oxidation resistance was different than for TBC spallation life [14]. Higher levels of Hf and Si were necessary to obtain optimum TBC life compared to lower levels for optimum oxidation resistance. The ability to process these coatings with reproducible compositions and structures has been an issue, although progress has been made [15].

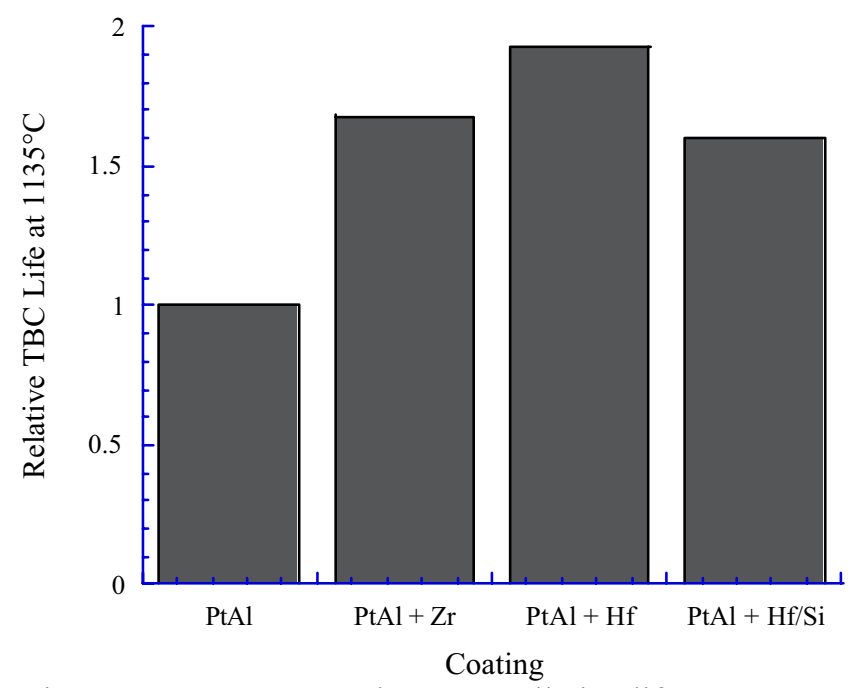

Figure 4. Improvements in $\mathrm{TBC}$ spallation life at $1135^{\circ} \mathrm{C}$ for various elemental additions to the PtAl bondcoat. 
In addition to bond coat compositional modifications to improve TBC life, it has been possible to introduce surface modifications to the PtAl coating to improve TBC life. In the extreme, this can be accomplished by adding grooves to the PtAl surface by laser machining [16]. Figure 5 shows a typical example of these grooves. Figure 6 shows improvements in $\mathrm{TBC}$ spallation life of up to $2 \mathrm{X}$ were possible by spacing grooves $125 \mu \mathrm{m}$ apart. Improvements in TBC life are a function of groove spacing and geometry, and it is possible to get benefits of up to $5 \mathrm{X}$ TBC spallation life. This technique is applicable to new and repaired blades and has been demonstrated in engine testing.

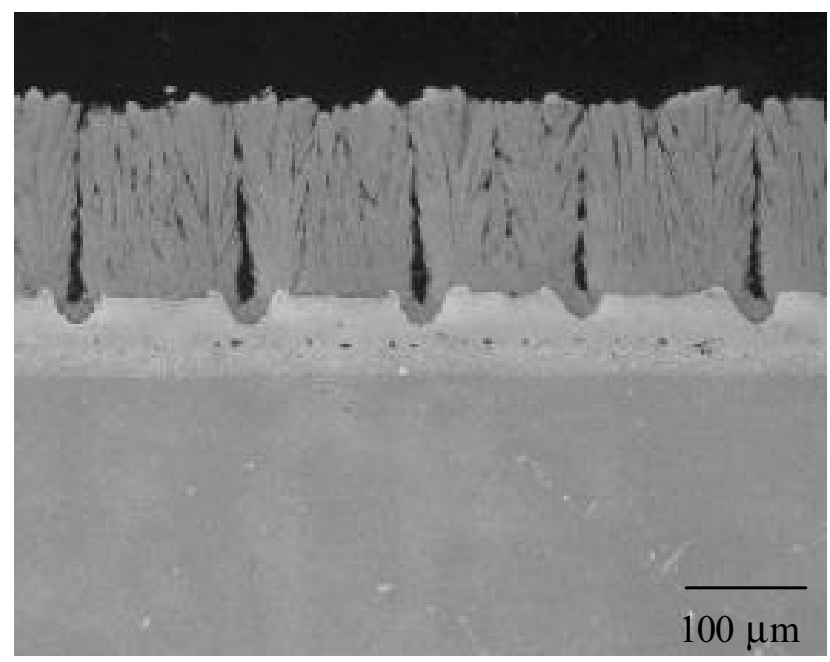

Figure 5. Laser machined grooves in a PtAl bondcoat.

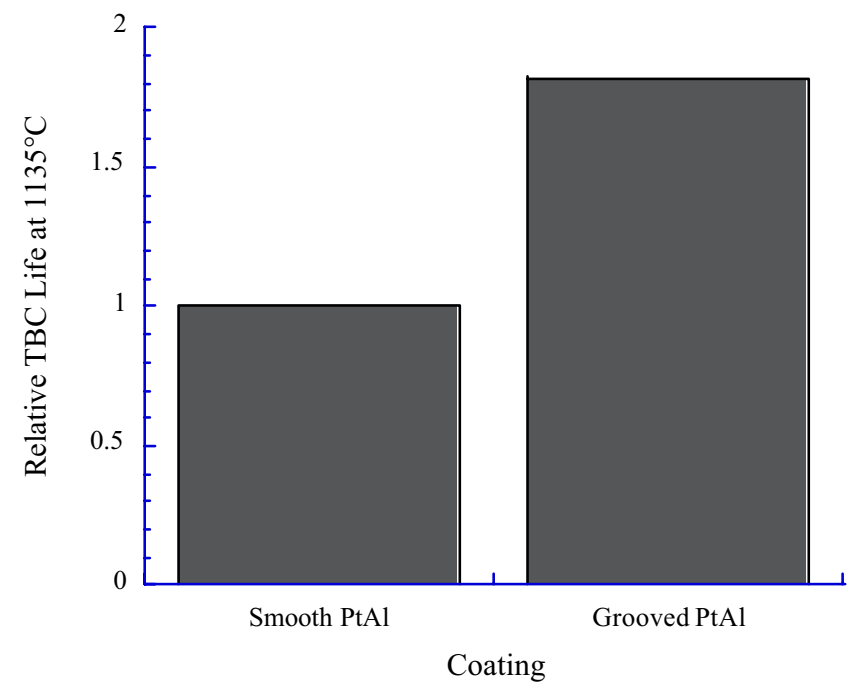

Figure 6. Beneficial effect of adding grooves with $125 \mu \mathrm{m}$ spacing on the TBC spallation life.
Another surface modification to PtAl involves optimizing the TGO layer prior to applying the TBC. Many investigators have studied the effects of selective oxidation of the TGO in various atmospheres and at various temperatures $[11,17-20] . \quad$ It is believed that a pure $\alpha$ alumina scale is the preferred TGO prior to TBC application. There are other important factors, such as the oxide grain structure, presence of transient oxides and manner of oxide growth. Various oxidation treatments were applied to PtAl, and Figure 7 shows a representative result. Like the "no bond coat" system, achieving the optimum surface for TBC application was difficult, resulting in significant scatter in many of the data sets.

Selective oxidation treatments remain a viable, production friendly method to improve TBC spallation life without composition changes to the bondcoat.

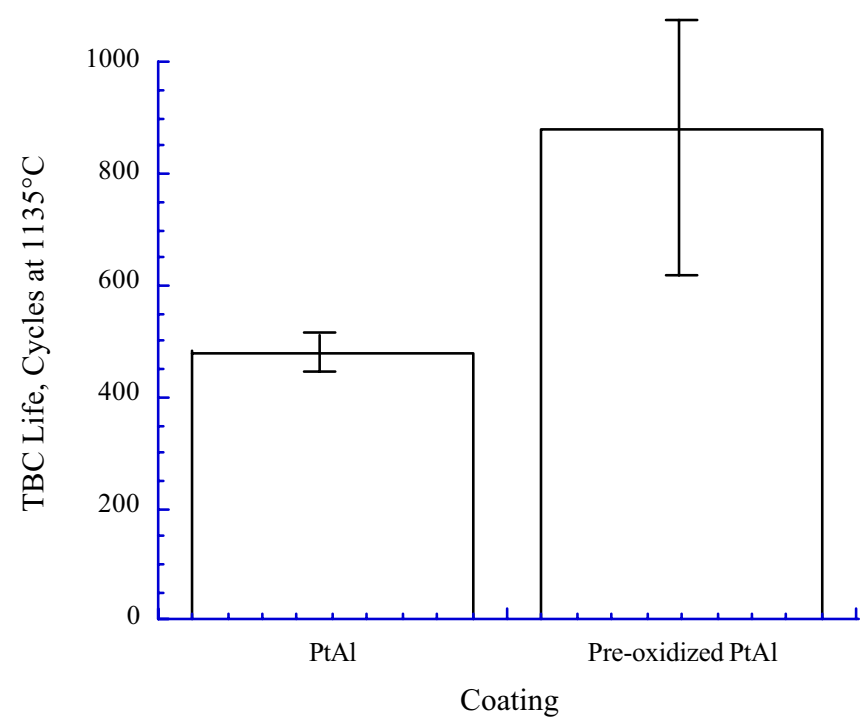

Figure 7. Selectively pre-oxidizing PtAl prior to TBC deposition can increase the TBC spallation life, however data scatter remains an issue.

One of the benefits of MCrAlY coatings is the ability to easily modify compositions to achieve improved environmental resistance or TBC adherence through modifications to the powder composition. By improving the oxidation kinetics of the MCrAlY coating, further improvements to TBC life can be attained. Figure 8 shows the benefit of adding a platinum or aluminide layer on top of a MCrAlY coating. The dual layer takes advantage of the MCrAlY composition effects and the improved oxidation kinetics due to the Pt or Al layer [8, 21]. 


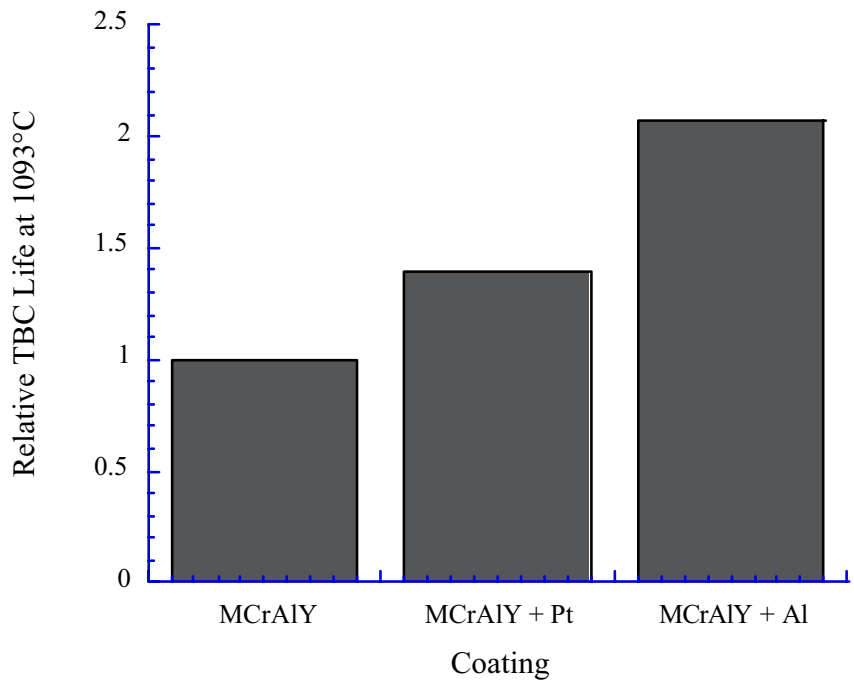

Figure 8. Benefit of adding an aluminide or PtAl layer on top of a MCrAlY coating

In summary, there are several methods that can be used to improve the bond coat performance. With continued understanding of the failure mechanisms of bond coats, it is believed that further advances are still possible through improved processing and composition modifications.

\section{Thermal Barrier Coating Improvements}

The application of thermal barrier coatings has resulted in significant temperature advances for turbine airfoils. To take further advantage of TBC systems, there are several areas for improvement. The primary purpose of TBC's is to insulate the metal substrate, and lowering the thermal conductivity of the standard $7 \mathrm{wt} \%$ yttria stabilized zirconia (7YSZ) is important to being able to increase the gas path temperature. However with increased usage and capability of TBC's, there can be surface temperature limitations, and these must also be addressed. In addition, the full benefit of TBC's cannot be realized until a more durable system is developed. One of the key components of a more reliant system is a TBC with improved impact resistance so that cooling air to the leading edge of the blade can be reduced, resulting in increased engine efficiency. The sections below discuss various improvements in each of these areas.

\section{Improved Impact Resistant TBC}

Impact resistance is a critical property for TBC's on turbine blades since the leading edge of the airfoil is subject to impact damage due to small particles in the gas stream, as shown in Figure 9. Since the early studies of thermal barrier coatings, the yttria stabilized zirconia (YSZ) family of compositions displayed the best balance of properties. $7 \mathrm{YSZ}$ is the current composition used by the entire industry for TBC applications on turbine airfoils and combustors. It is well known that as the yttria level is increased, the thermal conductivity decreases, however other properties, such as thermal spallation life and processability, are adversely affected as the yttria level increases beyond 7 wt.\%. Little work has been done on compositions with less than 7 wt.\% yttria because of phase stability concerns. However, at levels just below 7 wt.\% yttria, the amount of monoclinic phase is not thought to be a significant problem for EB-PVD columnar microstructures [22].

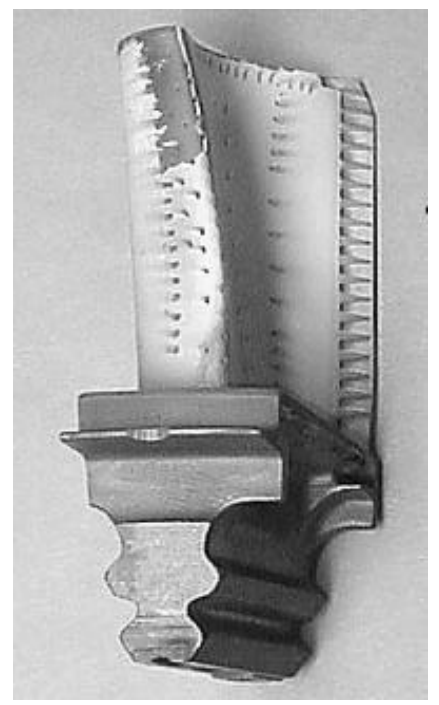

Figure 9. Turbine blade showing impact damage to the thermal barrier coating on the leading edge.

In order to assess impact resistance under conditions simulative of turbine blades in service, a test was developed where different size and types of particles could be introduced into the gas stream of a combustor burner rig at high temperatures and high velocities [23]. Figure 10 shows that the impact resistance of YSZ increases substantially below 7 wt.\% yttria. Likewise, the fracture toughness improves at lower levels of yttria [24] and follows the same trend as impact resistance. It was found that 4 wt.\% yttria represented a balance of processability, thermal conductivity and TBC spallation life, while resulting in a $2 \mathrm{X}$ improvement in impact resistance. This composition has been extensively evaluated and engine tested as a candidate for future applications. 


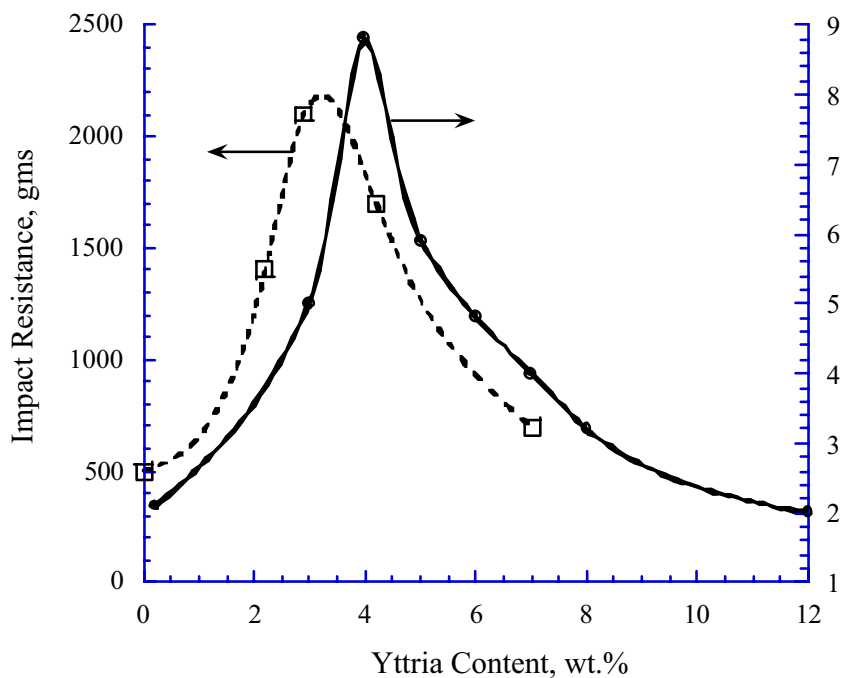

Figure 10. Room temperature fracture toughness [24] and $1232^{\circ} \mathrm{C}$ impact resistance of zirconia as a function of yttria content.

\section{Thermal Conductivity Reductions}

In order to maintain constant metal temperatures, while increasing the gas path temperature, the TBC thickness must be increased or the TBC thermal conductivity must be reduced. Increasing the TBC thickness is not attractive because it adds weight to the system and increases the surface temperature of the TBC. A TBC with lower thermal conductivity than 7YSZ could be utilized by either employing a thinner TBC or increasing the gas path temperature. Many investigators have been evaluating composition or process modifications to lower thermal conductivity [25-28]. While it has been shown to be possible to achieve conductivity decreases up to $50 \%$ over 7YSZ, it is difficult to achieve a balance of TBC spallation life, erosion and impact resistance, high temperature stability, cost and producibility. In particular, achieving adequate impact resistance while reducing thermal conductivity has proven to be difficult. After much evaluation, it has been shown in the zirconia system, that the phase stability is directly related to impact and erosion resistance. Figure 11 shows that as the amount of total stabilizer added to zirconia increases, the impact and erosion resistance are significantly reduced. Although the mechanisms for impact and erosion degradation of TBC are different, the relative effects of compositional modifications are the same and can be plotted together. While this effect was previously known for yttria, it appears that a wide variety of other additions to zirconia have a similar effect of degrading the impact and erosion resistance. Note the similar shape of the curves in Figures 10 and 11 beyond additions of $7 \mathrm{wt} . \%$ or $4 \mathrm{~mol} \%$. This loss of impact resistance represents a serious issue for the implementation of low conductivity TBC's and must be addressed through coating modifications or utilization of non-zirconia systems that meet the required balance of properties.

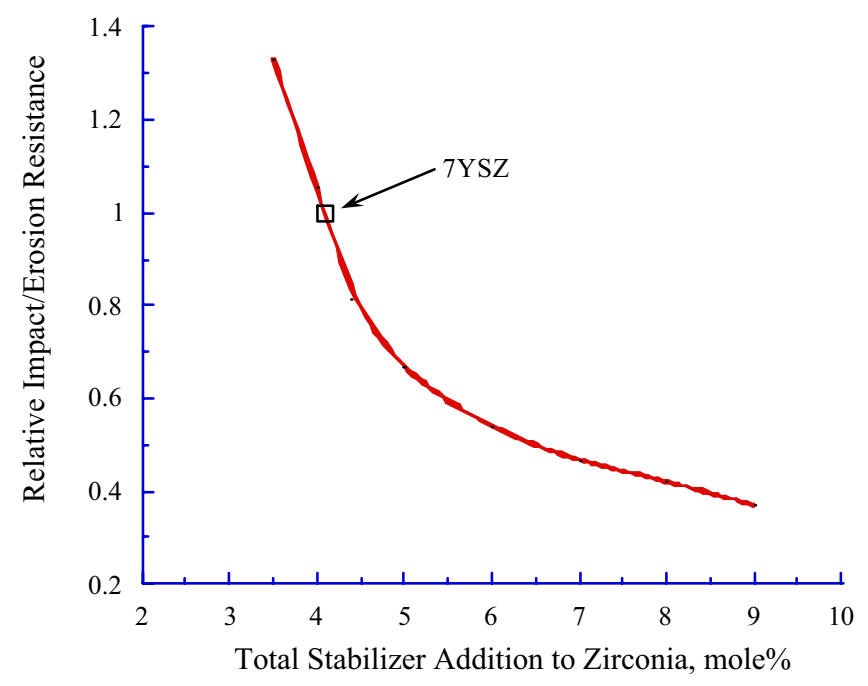

Figure 11. Loss of impact and erosion resistance as a function of composition modifications to zirconia.

\section{CMAS Issue and Mitigation}

Areas of the turbine blade that do not experience impact or erosion conditions typically have deposits as a result of sand and other natural substances entering the engine. These deposits are benign under most conditions, however at high temperatures they can form a low melting eutectic containing calcia, magnesia, alumina and silica (CMAS). Above the eutectic temperature, the molten CMAS deposit can infiltrate the columnar EB-PVD TBC. Upon cooling, the TBC columns containing the CMAS deposits are not able to accommodate the strain, leading to cracking and premature spallation. As turbine inlet temperatures continue to increase, it becomes critical to develop mitigation techniques to avoid the detrimental effects of CMAS deposits. Many different mitigation techniques have been evaluated including composition and structure modifications to the TBC and additional layers on top of 7YSZ TBC [29,30]. The most effective mitigation technique to date has been the application of a thin layer of alumina on top of the TBC, as shown in Figure 12. The alumina reacts with the CMAS deposit and raises the 
melting temperature of the deposit so that it is not able to infiltrate the TBC and cause premature spallation. The effectiveness of the alumina layer was tested in a rig using a propane torch to generate high surface temperatures along with backside cooling to create significant thermal gradients through the specimen. Deposits with the CMAS composition were applied to specimens, as shown in Figure 13. This figure shows the effectiveness of the alumina mitigation in preventing TBC spallation due to the simulated CMAS deposit. Figure 13 shows the effect on a plasma sprayed TBC, but similar beneficial effects have been demonstrated on EB-PVD TBC. This CMAS mitigation system has been engine tested and is being implemented to allow for higher TBC surface temperatures.

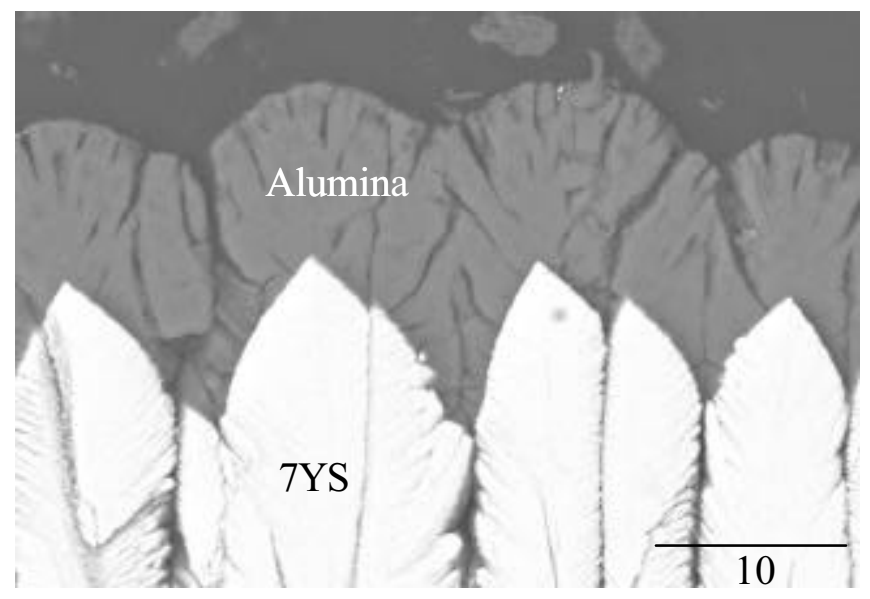

Figure 12. Thin alumina layer deposited on top of 7YSZ to improve resistance to CMAS-induced TBC spallation.

\section{Non-Airfoil Surface Improvements}

As turbine inlet temperatures continue to increase, the effect on the entire turbine airfoil must be considered. While the bond coat and TBC improvements discussed above are valid for the airfoil surface, they do not necessarily address the non-flowpath areas under the platform of the blade, the internal surfaces and the turbine blade tip. These sections will describe some of the issues with higher temperatures and material solutions.

\section{Root and Internal Surfaces}

The area under the platform of a turbine blade is susceptible to hot corrosion due to particulates that are carried in the cooling air of the turbine and deposited under the blade platform. As engine temperatures increase, this area enters the Type II hot corrosion regime [31]. The corrosion susceptibility is a function of engine operating conditions, airline and flight patterns. While a simple aluminide will increase the corrosion resistance under the platform of the turbine blade, occasionally the increased corrosion resistance of PtAl is required. For over 10 years, GE Aircraft Engines has routinely been applying PtAl under the platform of some helicopter turbine blades to successfully avoid hot corrosion. Figure 14 shows a turbine blade that has experienced corrosive conditions and the effectiveness of a PtAl coating in preventing the corrosion of the base metal. As temperatures in other engines have become hotter, this has now become common on many high pressure turbine blades.

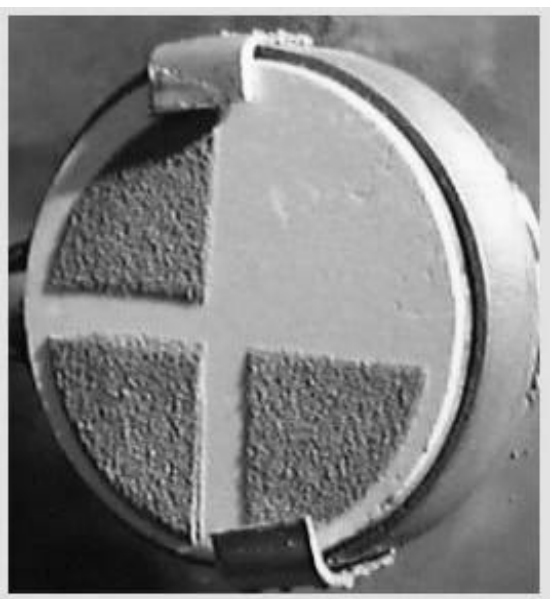

(a)

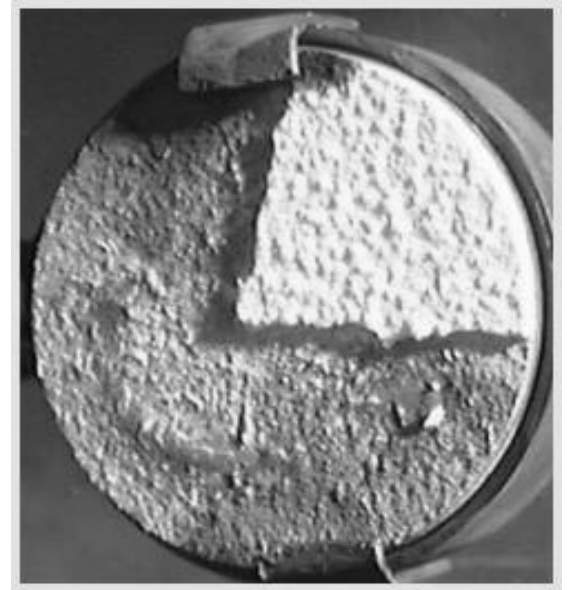

(b)

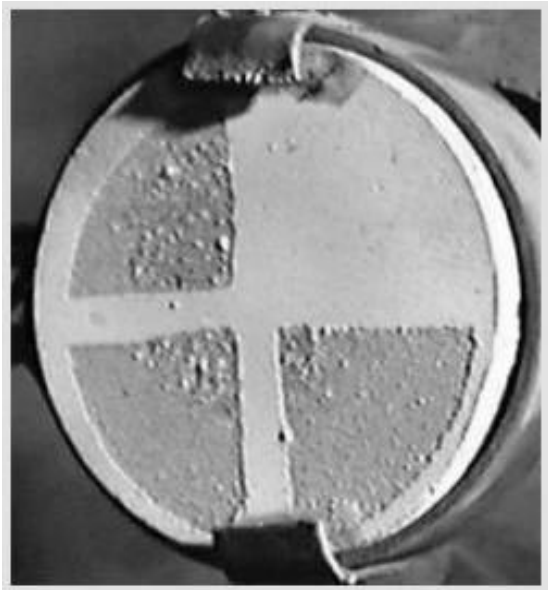

(c)

Figure 13. (a) Specimen with three quadrants of synthetic CMAS of varying thicknesses prior to test. (b) Following a thermal gradient test with spallation in the three CMAS quadrants. (c) Tested specimen coated with the alumina coating on top of TBC showing no spallation. 


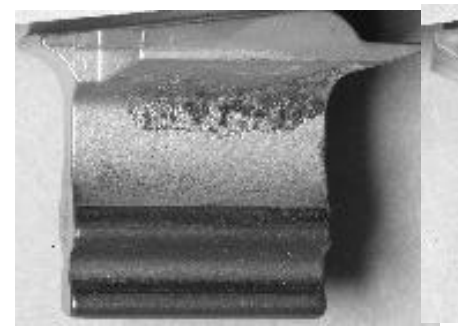

(a)

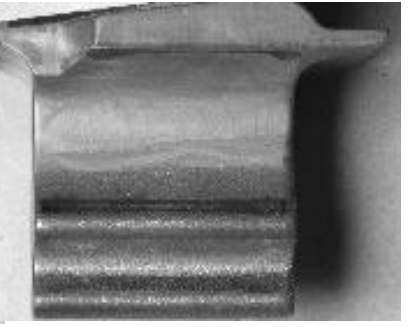

(b)
Figure 14. (a) Uncoated turbine blade showing underplatform corrosion after field service. (b) Turbine blade with PtAl coating under the platform showing an absence of corrosion.

Likewise, historically the internal surfaces of turbine blades were not coated. With the increase in temperatures, it is now commonplace to apply an aluminide coating to the internal surfaces of turbine blades. This has been very successful in reducing the amount of low temperature oxidation degradation compared to bare internal surfaces.

\section{Turbine Blade Tips}

Turbine blade tips tend to be one of the hottest areas of the turbine blade, and the oxidation resistance of the tips becomes critical to the life and performance of the blade. For advanced applications, a new superalloy, René 195, has been developed that can be welded onto the turbine blade tip, resulting in extended life for the blade system [32]. This superalloy is similar to the second generation single crystal superalloy, René N5 (Table I). The Al content was increased to improve oxidation resistance, and Ta was decreased to improve weldability by minimizing strain age cracking. These composition modifications achieved the goal of adequate strength with excellent oxidation resistance, as shown in Figure 15. René N5 is known to have the best oxidation resistance of single crystal superalloys, so it is a significant accomplishment to achieve even better oxidation resistance in René 195 . This is illustrated further in Figure 16, which shows the welded René 195 tip on top of a René N5 specimen that was oxidation tested at $1204^{\circ} \mathrm{C}$ simulating the improved oxidation performance that would be expected on a welded turbine blade. René 195 has been extensively tested and has been approved for production release.

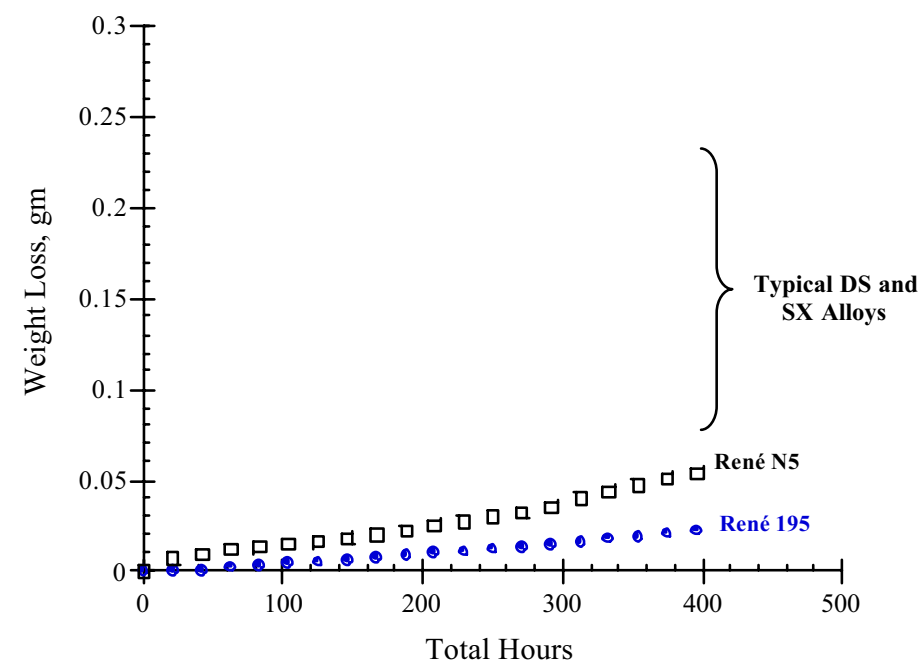

Figure $15.1204^{\circ} \mathrm{C}$ oxidation test results showing the performance of the René 195 tip alloy compared to René N5 and the typical range observed for other superalloys.

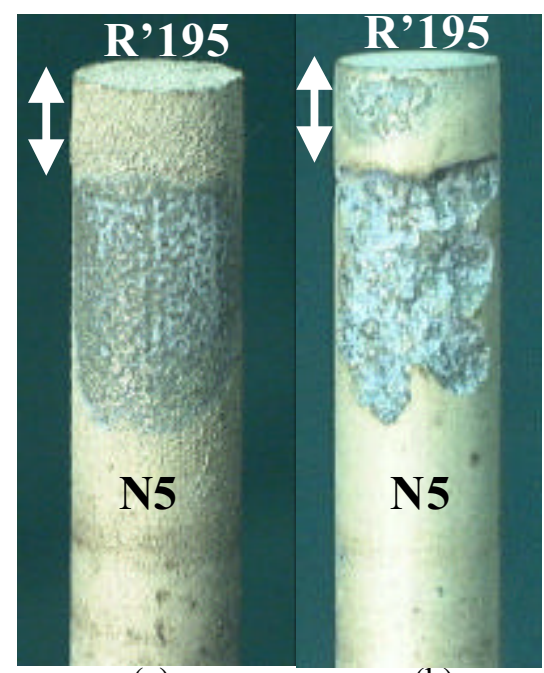

(a)

Figure 16. Oxidation pins after testing at $1204^{\circ} \mathrm{C}$ for 400 hours. René 195 alloy was welded onto the tip of the René N5 pin and shows significantly less oxidation attack in both the (a) aluminide coated condition and (b) bare condition.

Table I. Composition of a New Turbine Blade Tip Alloy, René 195.

\begin{tabular}{|c|c|c|c|c|c|c|c|c|c|c|c|}
\hline Alloy & $\mathrm{Cr}$ & $\mathrm{Co}$ & $\mathrm{Al}$ & $\mathrm{Ta}$ & $\mathrm{Mo}$ & $\mathrm{W}$ & $\mathrm{Re}$ & $\mathrm{Hf}$ & $\mathrm{C}$ & $\mathrm{B}$ & $\mathrm{Ni}$ \\
\hline René 195 & 7.6 & 3.1 & 7.8 & 5.5 & 0.1 & 3.9 & 1.7 & 0.15 & 0.02 & 0.015 & Bal. \\
\hline René N5 & 7.0 & 7.5 & 6.2 & 6.5 & 1.5 & 5.0 & 3.0 & 0.15 & 0.05 & 0.004 & Bal. \\
\hline
\end{tabular}




\section{Summary and Conclusions}

In summary, as the advances in single crystal superalloys become more difficult, one must look to other areas, such as coatings, to provide increased temperature capability. There are several approaches to improving the bond coat capability, ranging from a no bond coat system to a strengthened PtAl to a multi-layer approach. Each of these has advantages and disadvantages associated with cost, manufacturability, reproducibility or weight. Continued understanding of the failure mechanisms and service limitations of these coatings will result in more improved bond coats in years to come.

There is a large amount of current research and development in the area of thermal barrier coatings because of their ability to very significantly increase the temperature capability of the turbine airfoil material system. While there are many approaches to reducing the thermal conductivity relative to $7 \mathrm{YSZ}$, most of these approaches create issues with impact and erosion resistance. Understanding the relationship between impact resistance and composition and processing will be key to developing a well-balanced, next generation TBC. Another limitation to increasing the temperature capability of TBC is the surface temperature limits imposed by engine dirt accumulation (CMAS). It was shown that it is possible to mitigate the detrimental effects of CMAS by applying various surface treatments, including an alumina overcoat.

Finally, the non-airfoil surfaces of the turbine blades must be equally considered in order to advance the temperature capability of the entire system. A new tip alloy with improved oxidation resistance was developed that is significantly more durable at higher temperatures than the latest single crystal superalloy blade materials. The oxidation and corrosion concerns in other areas of the blade, such as under the platform or internal surfaces must be addressed by the proper application of coatings. With this system approach, the temperature capability of the entire turbine blade can be increased, resulting in higher turbine inlet temperatures and more efficient aircraft engines.

\section{References}

1. W.S. Walston, K.S. O’Hara, E.W. Ross, T.M. Pollock and W.H. Murphy, "René N6: Third Generation Single Crystal Superalloy", Superalloys 1996, ed. R.D.. Kissinger, et al, (Warrendale, PA: TMS, 1996), 27-34.

2. G.L. Erickson, "The Development and Application of CMSX-10", Superalloys 1996, ed. R.D.. Kissinger, et al, (Warrendale, PA: TMS, 1996), 35-44.

3. W.S. Walston, J.C. Schaeffer and W.H. Murphy, "A New Type of Microstructural Instability in Superalloys - SRZ”, Superalloys 1996, ed. R.D.. Kissinger, et al, (Warrendale, PA: TMS, 1996), 9-18.

4. J.L. Smialek, "Oxidation Resistance and Critical Sulfur Content of Single Crystal Superalloys", ASME IGTI Turbo Expo, (New York, NY: ASME, 1996), 96-GT519.

5. J.C. Schaeffer, W.H. Murphy, J.L. Smialek, "The Effect of Surface Condition and Sulfur on the Environmental Resistance of Airfoils", Oxidation of Metals, Vol. 43, No. 1/2, (1995), 1-23.

6. W.S. Walston, J.C. Schaeffer, W.H. Murphy, "Low Sulfur Article Having a Platinum Aluminide Protective Layer and its Preparation", U.S. Patent 6,333,121, (2001).

7. J.C. Schaeffer, W.H. Murphy, W.B. Connor, B.A. Nagaraj, H.B. Vakil, "Thermal Barrier Coating System Having No Bond Coat", U.S. Patent 5,538,796 (1996).

8. B.A. Nagaraj, W.B. Connor, R.W. Jendrix, D.J. Wortman, L.W. Plemmons, "Platinum, Rhodium or Palladium Protective Coatings in Thermal Barrier Coating Systems", U.S. Patent 5,427,866, (1995).

9. J.C. Schaeffer, M.A. Rosenzweig, N.R. Lindblad, W.H. Murphy, "Low Sulfur Article Coated with a Platinum-Group Metal and a Ceramic Layer, and its Preparation", U.S. Patent 6,656,605, (2003).

10. A.G. Evans, D.R. Mumm, J.R. Hutchinson, G.H. Meier, F.S. Pettit, "Mechanisms Controlling the Durability of Thermal Barrier Coatings", Progress in Materials Science, 46(5), (2001), 505-553.

11. I.T. Spitsberg, D.R. Mumm, A.G. Evans, "On the Failure Mechanisms of Thermal Barrier Coating Systems Incorporating Diffusion Aluminide Bond Coatings", to be published in Journal of Materials Research, (2004). 
12. W.S. Walston, R.D. Field, J.R. Dobbs, D.F. Lahrman, R. Darolia, "Microstructure and High Temperature Strength of NiAl Alloys", Structural Intermetallics, ed. R. Darolia, et al, (Warrendale, PA: TMS, 1993), 523532.

13. Enabling Propulsion Materials Program, Contract NAS3-26385.

14. J.D. Rigney, R. Darolia, W.S. Walston, "Article with Hafnium-Silicon Modified Platinum Aluminum Bond or Environmental Coating”, U.S. Patent 6,514,629, (2003).

15. B. Warnes, D. Near, D. Punola, W. Basta, "Active Element Modified Platinum Aluminide Diffusion Coating and CVD Coating Method", U.S. Patent 6,091,014, (2001).

16. D.W. Skelly, et al, "Enhanced Thermal Barrier Coating System", U.S. Patent 5,419,971, (1995).

17. W. Lih, E. Chang, B.C. Wan, C.H. Chao, Effect of Preoxidation on the Properties of $\mathrm{ZrO}_{2}-8 \mathrm{Wt} \% \mathrm{Y}_{2} \mathrm{O}_{3} / \mathrm{Ni}-$ 22Cr-10Al-1Y Thermal Barrier Coatings", Oxidation of Metals, 36(3,4), (1991), 221-238.

18. T.E. Strangman, P.A. Solfest, "Ceramic Thermal Barrier Coatings with Alumina Barrier Interlayer", U.S. Patent 5,015,502, (1991).

19. N.E. Ulion, N.P. Anderson, "Advanced Thermal Barrier Coated Superalloy Components", U.S. Patent 5,262,245, (1993).

20. B. Warnes, J. Cockerill, J. Schilbe, “Thermal Barrier Coating Method", U.S. Patent 6,472,018, (2002).

21. B.K. Gupta, J.D. Reeves, B.A. Nagaraj, "Method for Increasing the Cyclic Spallation of a Thermal Barrier Coating”, U.S. Patent 5,236,745, (1993).

22. R.W. Bruce, D.J. Wortman, R. Viguie, D.W. Skelly, "Thermal Barrier Coating System", U.S. Patent 5,981,088, (1999).

23. R.W. Bruce, "Development of $1232^{\circ} \mathrm{C}$ Erosion and Impact Tests for Thermal Barrier Coatings", Tribological Trans., 41(4), (1998), 399-410.

24. R.P. Ingel, D. Lewis, B.A. Bender, R.W. Rice, "Physical, Microstructural and Thermomechanical Properties of $\mathrm{ZrO}_{2}$ Single Crystals", Advances in Ceramics: Vol. 12, Science and Technology of Zirconia II, ed. N. Claussen, et al, (Columbus, OH : American Ceramic Society, 1983), 408-414.

25. J. R. Nicholls, K. J. Lawson, A. Johnstone, and D.S. Rickerby; "Methods to Reduce the Thermal
Conductivity of EB-PVD TBC's", Surface and Coatings Technology, 151-152, 2002, 383-391.

26. M. Maloney, "Thermal Barrier Coating Systems and Materials”, U.S. Patent 6,284,323, (2001).

27. P. Lawton and L. Y. Liu, "A New EBPVD TBC with Low Thermal Conductivity, Long Lifetime and Low Cost (3L coating)", Turbine Forum 2004 - Advanced Coatings for High Temperatures, Nice, France, 2004.

28. T.E. Strangman, D. Raybould, "Low Conductivity Barrier Coating”, U.S. Patent 6,482,537, (2002).

29. W. Hasz, C. Johnson, M. Borom, "Protection of TBC by Sacrificial Surface Coating”, U.S. Patent 5,660,885, (1997).

30. W. Hasz, M. Borom, C. Johnson, "Protection of TBC with an Impermeable Barrier Coating", U.S. Patent 5,871,820, (1999).

31. F.S. Pettit, C.S. Giggins, "Chapter 12 - Hot Corrosion", Superalloys II, ed. C.T. Sims, et al, (New York, NY, Wiley \& Sons, 1987), 327-358.

32. C. Mukira, M. Jackson, J. Schaeffer, S. Walston, T. Broderick, "Superalloy Weld Composition and Repaired Turbine Engine Component", U.S. Patent 6,468,367, (2002).

\section{Acknowledgements}

This paper reflects the efforts of a large number of people over many years. The real credit belongs to those people, which include Ben Nagaraj, Joe Rigney, Ram Darolia, Irene Spitsberg, Robert Bruce, Brett Boutwell, Kevin O’Hara, Wendy Murphy, Tom Kelly, and Janet Gaewsky at GE Aircraft Engines; Curt Johnson, Mel Jackson, and Dave Wortman at GE Corporate R\&D; and Jon Schaeffer at GE Power Systems. 